is naturaleza 
Para la publicación de este número se ha contado con la ayuda

financiera de las siguientes instituciones:

Departamento de Filosofía y Lógica y Filosofía de la Ciencia de la Universidad de Sevilla

Facultad de Filosofía de la Universidad de Sevilla 


\section{NATURALEZA Y LIBERTAD}

Revista de estudios interdisciplinares

Número 4

Málaga, 2014

Esta revista es accesible on-line en el siguiente portal:

http://grupo.us.es/naturalezayl 


\section{Naturaleza y Libertad}

Revista de estudios interdisciplinares

Número 4

ISSN: 2254-96682014

Directores: Juan Arana, Universidad de Sevilla; Juan José Padial, Universidad de Málaga; Francisco Rodríguez Valls, Universidad de Sevilla.

Secretaria: Avelina Cecilia Lafuente, Universidad de Sevilla.

Consejo de Redacción: Jesús Fernández Muñoz, Universidad de Sevilla; José Luis González Quirós, Universidad Juan Carlos I, Madrid; Francisco Soler, Universität Dortmund / Universidad de Sevilla; Pedro Jesús Teruel, Universidad de Valencia; Héctor Velázquez, Universidad Panamericana, México.

Adjunto a la redacción: Miguel Palomo, Universidad de Sevilla

Consejo Editorial: Mariano Álvarez, Real Academia de Ciencia Morales y Políticas; Allan Franklin, University of Colorado; Michael Heller, Universidad Pontificia de Cracovia; Manfred Stöcker, Universität Bremen; William Stoeger, University of Arizona.

Consejo Asesor: Rafael Andrés Alemañ Berenguer. Universidad de Alicante; Juan Ramón Álvarez, Universidad de León; Luciano Espinosa, Universidad de Salamanca; Miguel Espinoza, Université de Strasbourg; Juan A. García González, Universidad de Málaga; José Manuel Giménez Amaya, Universidad de Navarra; Karim Gherab Martín, Urbana University, Illinois; Martín López Corredoira, Instituto de Astrofisica de Canarias; Alfredo Marcos, Universidad de Valladolid; Marta Mendonça, Universidade Nova de Lisboa; Javier Monserrat, Universidad Autónoma de Madrid; Leopoldo Prieto, Colegio Mayor San Pablo, Madrid; Ana Rioja, Universidad Complutense, Madrid. Madrid; José Luis González Recio, Universidad Complutense, Madrid; Javier Serrano, TEC Monterrey (México); Hugo Viciana, Université Paris I; Claudia Vanney, Universidad Austral, Buenos Aires; José Domingo Vilaplana, Huelva.

\section{Redacción y Secretaria:}

Naturaleza y Libertad. Revista de estudios interdisciplinares. Departamento de Filosofia y Lógica. Calle Camilo José Cela s.n. E-41018 Sevilla.

Depósito Legal: MA2112-2012

욜 954.55.77.57 Fax: 954.55.16.78. E-mail: jarana@us.es

(C) Naturaleza y Libertad. Revista de Filosofía, 2014 


\section{ÍNDICE}

\section{ESTUDIOS}

Manuel Alfonseca (Universidad Autónoma de Madrid), Diseño inteligente, evolución al azar, o evolución providencial....... ..11

Paul Gilbert, S J (U. Gregoriana, Roma), Deseo de conocer ..............................................27

Javier Hernández-Pacheco (U. de Sevilla), Evolución, erotismo y origen de las especies. De vuelta desde Darwin a Platón y Aristóteles.

Miguel Ángel Herrero (U. Politécnica de Madrid), La formación de los conceptos científicos. De Grosseteste a Galileo.

Ma Teresa Pelacho López (Zaragoza), Otra autonomía de la ciencia. Reflexiones a la luz del pensamiento de Serguei Kara-murzá.......

Juan Fernando Sellés (U. de Navarra), Estudio de las tesis centrales de Millán-Puelles sobre la libertad....... 189

Francisco Soler Gil (U. de Sevilla), El naturalismo y la tentación de las extrapolaciones omnicomprensivas.

Héctor Velázquez Fernández (U. Panamericana, México), En torno a la naturalización de la conciencia sugerida por Daniel Dennett

\section{SECCIÓN BIBLIOGRÁFICA}

Maria Camila Gallego: Falsos saberes.

Juan Arana: Bernardino Telesio, La naturaleza según sus propios principios. 


\title{
ESTUDIO DE LAS TESIS CENTRALES DE MILLÁN- PUELLES SOBRE LA LIBERTAD
}

\author{
Juan Fernando Sellés \\ Universidad de Navarra
}

\begin{abstract}
Resumen: en este trabajo se revisan 9 tesis centrales de Millán-Puelles sobre la libertad humana: $1^{\text {a) }}$ Es accidente, no sustancia; se 'tiene', no se 'es'. 2a) Respecto de su 'sujeto', depende de un principio o causa; $3^{a}$ ) Respecto de su 'objeto', es 'libertad de indiferencia'. 4a) Es de dos tipos: una inferior, innata; y otra superior, adquirida. $5^{\text {a }}$ ) La innata es triple: la doble 'trascendental' del entendimiento y de la voluntad y el libre albedrío de la voluntad. 6a) La adquirida es doble: la civil y la moral. $7^{\text {a }}$ ) Deriva de la necesidad y se subordina a ella. 8a) Es limitada. 9a) Su forma máxima es la 'elección' de Dios.
\end{abstract}

Palabras clave: Millán-Puelles, naturaleza, libertad, dignidad humana, accidente.

Abstract: In this work we study the 9 principal thesis about the freedom in the MillánPuelles's anthropology: 1a) Human freedom is an accident, not the human substance; we 'have' freedom, but we 'are not' freedom. $2^{\mathrm{a}}$ ) The 'subject' of human freedom depends on one principle or cause. $3^{\text {a) }}$ Respect of its 'object' the human freedom is 'of indifference'. 4a) Human freedom admits two types: one inferior, innate, and another superior, acquired. $5^{\text {a }}$ Innate freedom is triple: the double 'transcendental' of the knowledge and of the will, and the 'liberum arbitrium' of the will. $6^{\text {a) }}$ Acquired freedom is double: civil and moral. 7a) Human freedom derivates from necessity and is subordinate to it. $8^{a}$ ) Human freedom is limited. 9a) Its highest form of human freedom is the 'choice' of God. Key words: Millán-Puelles, nature, freedom, human dignity, accident.

Recibido: 02/06/2013. Aprobado: 06/09/2013 
Naturaleza y Libertad. Revista de estudios interdisciplinares. Número 4, 2014. ISSN: 2254-9668

\section{PRESENTACIÓN}

La entera filosofía de Antonio Millán-Puelles (1921-2005) constituye una meditación en torno a la libertad humana, por lo que se puede indicar que este trabajo atiende al centro neurálgico de su pensamiento ${ }^{1}$. Su concepción de la libertad a lo largo de toda su obra se puede sintetizar en las tesis que se enunciarán a continuación en el título de cada uno de los epígrafes de este trabajo. Pero antes de formularlas, debe tenerse en cuenta que el pensador gaditano entiende al hombre como un compuesto de sustancia y accidentes $^{2}$, modelo según el cual el alma y el cuerpo conforman la sustancia, a la que también denomina 'naturaleza' 'esencia', 'sujeto', 'persona', 'ser', mientras que pertenecen a los accidentes las potencias inmateriales humanas —entendimiento y voluntad-y, según el autor, las dos dimensiones más relevantes inherentes en ellas: el autoconocimiento y la libertad.

1 Según F. J. Martínez López, "el binomio naturaleza-libertad es en la filosofía de MillánPuelles una de las claves interpretativas de su antropología”. La fundamentación de la ética realista. Valoración de la propuesta de A. Millán-Puelles, Tesis Doctoral, Roma, Universidad de la Santa Cruz, 1999, p. 264. Del mismo modo, para J. J. Eres Brun, "naturaleza y libertad son las dos dimensiones que dan razón de la condición humana”. La libre realización del hombre según Antonio Millán-Puelles (Fundamentos para una antropología), Tesis Doctoral, Roma, Universidad de la Santa Cruz, 2005, p. 225

2 Cfr. J. M. Barrio, "Dignidad y trascendencia de la persona. Una panorámica de la antropología de Antonio Millán-Puelles”, en: Propuestas antropológicas del s. XX (I), J. F Sellés (ed.), Pamplona, Eunsa, 2a ed., 2006, pp. 47-75. Para uno de los conocedores de la filosofía del pensador gaditano "lo primero que llama la atención en la antropología de Millán Puelles es su claro y resuelto sustancialismo". M. Bicocca, La persona humana y su formación en Antonio Millán-Puelles, Pamplona, Eunsa, 2011, p. 28. 
En la exposición se procederá del siguiente modo: tras enunciar cada una de las tesis a modo de encabezamiento de los respectivos epígrafes se pasará: a) en primer lugar, a explicitar su significado; b) en segundo lugar, a ratificar dicha tesis teniendo en cuenta los textos del autor a lo largo de su entera producción y respectando el orden cronológico de composición de sus obras; c) por último, se formularán unas preguntas, por considerar que en ellas queda algo por esclarecer y fundamentar, al menos, para el autor de este trabajo. Tanto el primer como el tercer apartados serán breves, dejando más espacio al segundo, o sea, a la exposición textual de la tesis, sobre todo, porque lo que más interesa es atender a las propias palabras del autor. Por lo demás, se citarán sus obras según las abreviaturas que se anotan ${ }^{3}$. Las tesis centrales que se recogen sobre la libertad según Millán-Puelles son:

3 Por orden cronológico, las obras — artículos y libros - en los que Millán-Puelles estudia el tema de la libertad son las siguientes: "La idea de la libertad en Jaspers", Arbor (65) 1951, pp. 61-65 (ILJ); Ontología de la existencia histórica, Madrid, ed. J. Pueyo, 1951 (OEH); Fundamentos de filosofía, Madrid, Rialp, 1955 (FF) se citará la 2o ed., de 1958; "Maeztu y la defensa del espíritu”, Madrid, Amigos de Maeztu, 1957 (MDE); La claridad en filosofía y otros estudios, Madrid, Rialp, 1958 (CF); Persona bumana y justicia social, Madrid, Rialp, 1962, citaremos la 5a ed. de 1982 (PHJS); La formación de la personalidad humana, Madrid, Rialp, 1989 (FPH) se cita la ed. de 1963; "La dignidad de la persona humana", Atlántida (IV/14) 1966, pp. 573-577 (DPH); La estructura de la subjetividad, Madrid, Rialp, 1967 (ES); "En torno a la idea del 'yo", Estudios de Metafísica, 1971, pp. 9-13 (IY); Economía y libertad, Madrid, Confederación Española de Cajas de Ahorro, 1974 (EL); De economía y libertad, (1985) es una versión abreviada del precedente; Sobre el hombre y la sociedad, Madrid, Rialp, 1976 (SHS); Universidad y sociedad, Madrid, Rialp, 1976 (US); "Cinco lecciones sobre la libertad", Revista de Medicina de la Universidad de Navarra (XXV/1) 1981, pp. 59-63 (CLL); "El sentido trascendente de la existencia y la educación”, Revista Española de Pedagogía 
Naturaleza y Libertad. Revista de estudios interdisciplinares. Número 4, 2014. ISSN: 2254-9668

\section{LA LIBERTAD HUMANA ES DEL PLANO DE LOS ACCIDENTES, NO DE}

\section{LA SUSTANCIA}

1.1. Explicación: Para Millán-Puelles la libertad humana se 'tiene' no se 'es'; pertenece al plano de los accidentes. Con todo, la libertad es un accidente 'propio', y es considerado un accidente tan valioso 'de la naturaleza humana' que la dignidad de la persona radica, junto con el entendimiento, en la libertad ${ }^{4}$, pues está engarzada hasta tal punto en la sustancia o naturaleza humana que parece dimanar de ella ${ }^{5}$.

(XL/158) 1982, pp. 57-60 (STE); “Amor a la libertad”, AA.VV., Homenaje a Monseñor

Josemaría Escrivá de Balaguer, Pamplona, Eunsa, 1986, pp. 25-49 (AL); "Maeztu y la libertad", Razón Española (IV/29) 1986, pp. 261-276 (ML); "La formación de la persona", AAVV., El pensamiento filosófico-pedagógico de Jacques Maritain, Madrid, San Pablo CEU, 1988, Colección Anales, (3) pp. 65-66 (FP); La libre afirmación de nuestro ser, Madrid, Rialp, 1994 (LAS); El valor de la libertad, Madrid, Rialp, 1995 (VL); Ética y realismo, Madrid, Rialp, 1996 (ER); "Las Humanidades y la Universidad”, Intus-Legere (1) 1998, pp. 16-28 (HU), y Léxico filosófico, Madrid, Rialp, 1984-2002 (LF) citaremos la 2a ed. de 2002.

4 Cfr. PHJS., p. 13; DPH., p. 114; EL., p. 414. En SHS dice explícitamente: "ese valor sustantivo, mensurante de la específica dignidad del ser humano, se llama 'libertad”, p. 99; cfr. también: pp. 183-184. Y en otro lugar se lee: "la dignidad de la persona humana $-\mathrm{y}$ de toda persona- está íntimamente unida al valor que la libertad tiene de suyo, de una manera intrínseca”. LF., p. 464.

5 Según esto, el del Prof. Millán, "es un planteamiento en el que la libertad brota espontáneamente de la misma raíz ontológica del existente humano". J. Arana, "Necesidad, libertad, Azar", Realidad e irrealidad. Estudios en homenaje al Profesor Millán-Puelles, Madrid, Rialp, 2001, p. 43. 
1.2. Ratificación textual: Esta tesis se encuentra desde el comienzo de los escritos de del pensador andaluz, a saber, desde sus estudios sobre Jaspers ${ }^{6}$, y Maeztu ${ }^{7}$. La encontramos asimismo en varios libros posteriores - La claridad en filosofía y otros estudios ${ }^{8}$, Persona bumana y justicia social $-\mathrm{y}$ se halla también en sus últimas obras.

Por ejemplo, en La formación de la personalidad humana el Profesor Millán vincula la educación y la libertad al entendimiento y a la voluntad, y como considera accidentes a estas facultades, también ve la libertad como accidente. En la Estructura de la subjetividad, como admite que la sustancia es la misma para toda la especie humana, al vincular la libertad a la sustancia, entiende la libertad es un accidente 'propio', permanente, peculiar: "la libertad, sustancialmente, idéntica, es la libertad de una misma sustancia, la sustancia bumana en general, dotada evidentemente en cada caso, de las respectivas diferencias individuales"10. Por tanto, la libertad es un hecho (factum) natural:

6 Cfr. "La palabra de la libertad jaspersiana pera entender al hombre individuo consiste en una penetrante alusión a la realidad de una sustancia íntima y originaria”. ILJ., p. 65. Cfr. asimismo: CIJ., p. 195;

7 "La naturaleza se nos aparece como 'sub-stancia' del comportamiento, como raíz de donde éste brota. No se halla, por tanto, en el mismo plano que la libertad. La libertad no puede ser sustancia... La capacidad de actuar libremente es, en el sujeto que la tiene y del que emanan los respectivos actos, un accidente al que mantiene y soporta una sustancia, que es la naturaleza... La libertad... no se 'soporta' a sí misma, no es, a pesar de todo, una sustancia, y, en consecuencia, necesita de ésta”, MDE, pp. 13-14.

8 Cfr. CF., p. 168.

9 Cfr. PHJS., p. 13.

10 ES., p. 315; cursivas en el original. 
"tan fáctico le es al hombre su ser libre, como al animal irracional su respectivo no serlo"11. También entiende al yo o sujeto como un 'factum', el cual ya está hecho, pero, por su libertad, puede hacerse en cierto modo, es decir, el sujeto es una sustancia con una libertad entendida como 'necesidad de optar'.

También en su artículo "En torno a la idea del "yo" secunda el modelo sustancia-accidentes, teniendo al yo como sustancia y a la libertad como accidente. Asimismo en Sobre el hombre y la sociedad vincula la libertad a la razón y a la voluntad, potencias que entiende como accidentes. Para armonizarlos con la naturaleza, o sea, para vincular lo accidental con lo sustancial, añade que tales accidentes son 'propios' del sujeto ${ }^{12}$. Nos dice que la razón y la voluntad no forman parte de la 'esencia metafísica del hombre', pero son, sin embargo, 'algo que ésta necesariamente requiere': la naturaleza humana 'necesita' esas facultades. Estas son 'accidentes necesarios', 'propiedades', 'propios'. A la par, estas facultades — como accidentes que son- 'necesitan' una 'sustancia' o 'naturaleza'. De acuerdo con este paradigma concluye que "la libertad no sólo no es incompatible con la naturaleza humana, sino que necesariamente la requiere, la exige, la supone"13. En suma, en esta obra comprende la libertad como algo que 'tenemos', pues "no somos la pura libertad"14, y cuyo fin es llegar a ser mediante ella el que ser que somos ${ }^{15}$.

11 ES., p. 410; cursivas en el texto original.

12 Cfr. SHS., p. 50.

13 SHS., p. 50.

14 SHS., p. 57. "El sujeto la tiene (libertad), pero no la es". Ibid., p. 60

15 Cfr. SHS., p. 56. 
En el libro El valor de la libertad el pensador de Alcalá de los Gazules mantiene que ninguna de las libertades que menciona (fundamental, libre albedrío, moral y política) pertenece a la 'esencia metafísica' del hombre, porque éste no 'es' libertad. Como define la 'esencia' humana como 'animal racional', admite que la "libertad no es lo mismo que animal racional"16. La razón que da es que

la libertad, por pertenecer a una de las potencias operativas humanas, no puede ser un componente o elemento de la esencia metafísica del hombre, donde no entra ninguna potencia operativa (pues todas ellas son accidentes, aunque necesariamente dimanen del constitutivo formal de nuestro ser) ${ }^{17}$.

Como se ve, el autor sigue, también en esta obra, el modelo sustancia-accidentes para describir al hombre, según el cual la libertad no es la sustancia (habría que explicitar que no es ni el cuerpo ni el alma ${ }^{18}$ ), sino un accidente, aunque éste derive necesariamente de aquélla. En suma, para el autor,

sólo estas dos potencias operativas (entendimiento y voluntad) son los inmediatos sujetos de atribución de la libertad humana innata. Y de ello, a su vez, se sigue que, en virtud de la

16 VL., p. 44.

17 Ibid., p. 44.

18 De ser éste el pensamiento de Don Antonio, parece que no podría aceptar que la libertad sea "una propiedad del alma en cuanto espiritual, que radica en ella antes que en sus potencias". T. Melendo, “Las dimensiones de la libertad”, en: Anuario Filosófico, 1994 (27/2), pp. 594-5. Más adelante este buen conocedor del pensamiento de Millán insiste en que "la naturaleza humana admite en su seno la libertad y su acrecentamiento". Ibid., p. 587. 
diferencia... del entendimiento y de la voluntad, hay dos libertades humanas de carácter innato: la propia de la facultad intelectiva y la peculiar de la facultad volitiva ${ }^{19}$.

En suma, se puede concluir, con una afirmación suya también de esta obra, que "si se piensa que el hombre es libertad — no que la tiene como necesariamente derivada de su específico ser- se termina, si se piensa con entero rigor lógico, negando toda esencia o naturaleza humana (recuérdese el claro ejemplo del existencialismo de Sartre)"20.

Por último, en Léxico Filosófico, Millán tampoco entiende la libertad como sustancia, pues escribe que "la libertad acentúa la individualidad, pero no se identifica con la subsistencia"21.

1.3. Cuestiones abiertas: Sobre esta tesis se pueden formular dos cuestiones: Por una parte, ¿jpor qué se hace girar la dignidad de la persona más sobre los accidentes que sobre la sustancia ${ }^{22}$ ? Por otra parte, ¿cómo un accidente (aun siendo 'propio') puede jugarse el destino eterno de la sustancia?

19 VL., p. 46; cursivas en el texto original.

20 Ibid., p. 76.

21 LF., p. 464.

22 En efecto, si se sostiene que la libertad está nativamente en la inteligencia y en la voluntad - y estas potencias se toman como accidentes-, habrá que sostener que la libertad es 'accidente'. Además, si se añade que la libertad 'está en la naturaleza', y si de la sustancia se declara 'que es la naturaleza', de la libertad hay que decir que está 'en la sustancia'; por tanto, que no la es; por tanto será accidente. Junto a eso se sostiene que la dignidad de la persona radica en el entendimiento y en la libertad, que son accidentes. 
Naturaleza y Libertad. Revista de estudios interdisciplinares. Número 4, 2014. ISSN: 2254-9668

2. EL HOMBRE POSEE DOS TIPOS DE LIBERTAD: LA INNATA Y LA ADQUIRIDA. LA ADQUIRIDA ES SUPERIOR (MÁS PERFECTA) A LA INNATA

2.1. Explicación: como se verá, el filósofo gaditano admite muchos tipos de libertad, pero todos ellos se reducen, según su origen, a dos: las que considera nativas o innatas, y las que son adquiridas. De las primeras es pertinente adelantar que las considera innatas en las potencias humanas superiores: la inteligencia y la voluntad; no innatas en la 'sustancia' o 'naturaleza' humana. De las adquiridas conviene anticipar que todas ellas se vinculan a una de esas dos aludidas facultades.

2.2. Ratificación textual: En artículo "Maeztu y la libertad" Millán-Puelles escribe que "la libertad presenta dos dimensiones mutuamente enlazadas, pero que es imprescindible distinguir: la libertad instrumental o de hecho y la ideal o final'23. Lo que en Maeztu es 'libertad instrumental, en Antonio MillánPuelles son la 'libertad trascendental' del entendimiento y la 'libertad psicológica de la voluntad'. Esto significa que tales facultades se hallan abiertas a todo. Por su parte, lo que en el primer humanista es la 'libertad final', en el segundo es la 'libertad moral'. Ambos autores consideran innatas a los dos tipos primeros de libertad y piensan que la segunda es adquirida, y es ésta última — para los dos—, por más perfecta, el fin de aquéllas. En su libro Economia y libertad llama a la 'libertad moral' libertad 'esencialmente humana', porque procura la 'humanización' de cada hombre, y por eso, la considera la más relevante ${ }^{24}$.

23 ML., p. 263

24 Cfr. EL., pp. 235 ss. 
En su trabajo "La formación de la persona" Millán-Puelles sostiene que una de las libertades innatas humanas se distingue de las otras en que se puede perfeccionar:

el libre albedrío humano es algo que ningún hombre se confiere a sí mismo, porque lo tiene ya en virtud, justamente, de su propia índole de hombre... Pero el libre albedrío no está dado al hombre de una manera puramente natural, y de ahí la posibilidad de educarlo. Patentemente, no se puede educar lo que de un modo unívoco se encuentra en su actividad o comportamiento. Y el hombre se hace hombre en la medida en que el uso que de su libertad lleva a cabo es el coherente con las exigencias objetivas —ideales, no físicas- de su propia naturaleza ${ }^{25}$.

Como se puede apreciar, el profesor Millán, además de seguir manteniendo que el libre albedrío es innato, y que, en cambio, su uso - que equivale a la 'libertad moral'- es adquirido, añade que el hombre se humaniza ('se hace hombre') con el uso moral — según virtud - del libre albedrío, lo cual indica que adquiere más perfección que la que nativamente tenía ${ }^{26}$.

25 FP., PP. 65-66.

26 Este mismo parecer lo mantiene un buen conocedor de su pensamiento: "qué duda cabe de que la libertad moral eleva a plenitud la condición y dignidad personales". T. Melendo, "Las dimensiones de la libertad", en: Anuario Filosófico, 1994 (27/2), p. 584. Y añade: "en ella (en la libertad moral)... alcanza su télos, su fin o plenitud la libertad del hombre”. Ibid., 585. Para este estudioso de Don Antonio, ser mejor persona es crecer en libertad moral: "este segundo acrecentamiento se realiza formalmente, apoyado en las otras dos libertades, gracias a lo que nuestro filósofo denomina libertad moral". Ibid. De manera que, siguiendo el adagio que menta que 'lo imperfecto es para lo más perfecto', sostiene que "la libertad fundamental se ordena al libre albedrío, y que uno y otro alcanzan su coronación en la libertad moral, que es la que permite al hombre actuar bien, y precisamente en cuanto hombre”. Ibid., p. 486. Por 
En el libro La libre afirmación de nuestro ser el pensador andaluz afirma que "nuestra libertad no se confunde con su efectivo ejercicio. Tenerla no es lo mismo que ejercerla"27, con lo que distingue entre libertad 'nativa' y su 'ejercicio'. Además, declara expresamente que "la perfección moral es la más alta entre todas las propias del hombre"28. También en su libro El valor de la libertad admite que por encima del valor del libre albedrío está la libertad moral ${ }^{29}$. Por último, en Léxico Filosófico el autor también da a entender que la libertad moral es superior a las innatas: "a esta libertad que no es innata, sino que puede y debe ser adquirida por el hombre para perfeccionar su propio

tanto, admite que "la libertad moral, si cabe, es más libertad que las otras dos". Ibid., p. 588, entre otras cosas porque nota que la moral es 'hábito', en el sentido de virtud, lo cual denota más perfección, más acto, que el mero acto de elección del libre albedrío, y mucha más que su mera 'capacidad de elegir', es decir, de ser 'potencia en orden al acto'. Pero de lo que no da cuenta este planteamiento es de cómo es posible que lo superior surja de lo inferior, el acto de la potencia.

27 LAS., p. 35.

28 LAS., p. 176.

29 "El libre albedrío humano no tiene el valor más alto entre todos los que el hombre puede poseer, porque por encima del valor de esta forma de libertad está el valor de la libertad que se consigue con las virtudes morales. La libertad de arbitrio, cuyo valor... es menos radical que el de la libertad trascendental del entendimiento y que el de la libertad trascendental de nuestra potencia volitiva, tiene un valor más radical que el valor de la libertad moral y, justamente por ello, menos alto. Lo más alto en el árbol es la copa, no la raíz". VL., p. 173. Más adelante agrega: "la libertad moral vale más que la pura y simple libertad humana de albedrío". Ibid., p. 176 (cfr. asimismo: Ibid., p. 188). A esta tesis añade que nuestra semejanza con el ser divino radica en la libertad moral (cfr. Ibid., p. 175). 
ser, cabe llamarla 'libertad moral', por lograrse en el ejercicio de esas mismas virtudes" 30 .

3.3 Cuestiones abiertas: A esta tesis cabe preguntar: ¿cómo puede ser superior, más perfecta, la libertad adquirida que la innata si nace de ella? Si la innata se considera potencial (se dice radicar en las facultades superiores en estado de potencia) y la segunda es activa (acto), ¿cómo surge el acto de lo enteramente potencial, lo perfecto de lo imperfecto?

\section{LA LIBERTAD HUMANA INNATA ES TRIPLE: LA 'TRASCENDENTAL' DEL ENTENDIMIENTO Y DE LA VOLUNTAD Y EL LIBRE ALBEDRÍO. LA LIBERTAD ADQUIRIDA ES DOBLE: LA CIVIL Y LA MORAL}

3.1. Explicación: Aunque Antonio Millán Puelles vincula mayormente la libertad a la voluntad ${ }^{31}$, al distinguir entre diversos tipos de libertad humana,

30 LF., p. 395. En una publicación sobre Millán-Puelles, se lee que, para éste, "el hombre se encuentra con un ser ya hecho - fácticamente constituido dirá el autor- el cual, sin embargo, es apto para trascender capaz de incrementar su propio ser abriéndose al ser en general. Ahora bien, en el pensamiento de Millán-Puelles la libertad establece un nexo entre la parte fija de nuestra naturaleza y la parte dinámica, ya que el uso reflexivo de nuestra libertad nos hace dueños de nuestra naturaleza”. A. Gutiérrez Rosado, La naturaleza humana como realidad trascendente en el pensamiento de Antonio Millán-Puelles, Tesis Doctoral, Roma, Universidad de la Santa Cruz, 2006, pp. 239-240.

31 Cfr. FF., P. 375; SHS., p. 48. "Ciertamente la libertad no es ningún atributo del entendimiento, ni tampoco del cuerpo, sino tan sólo de la facultad volitiva”. LF., p. 395. Y más adelante insiste: "la libertad pertenece formal y directamente a la voluntad, no a ninguna de las otras facultades imperables por ésta. El entendimiento humano no es formal o directamente libre; no procede por sí mismo libremente; pero puede actuar bajo el imperio de 
sostiene que la 'libertad trascendental', que considera innata, es, a su vez, doble: la apertura del entendimiento a conocer toda la realidad, y la apertura de la voluntad a querer todo bien ${ }^{32}$. Por su parte, el libre albedrío, al que considera innato, es la capacidad de la voluntad de elegir cualquier realidad. De entre estas tres libertades, la más básica es considerada la primera; la más excelsa, la tercera. Por su parte, la libertad humana adquirida es, según el autor, doble: la civil o política y la moral. Ambas presuponen (surgen de) las libertades innatas.

3.2. Ratificación textual: En Economía y libertad Millán-Puelles habla de la 'libertad de la razón'33. Se trata de una 'libertad fundamental'34, es decir, de la apertura nativa de la inteligencia. Por su parte, en esta obra el autor indica que con el libre albedrío

cuenta el hombre con un dominio y señorío de ciertos actos suyos y se vive a sí propio como el origen de ellos y no tan solo como el escenario en el cual se ejecutan. Tal libertad es, pues, la propiedad por la que cabe decir que de un modo efectivo somos protagonistas de lo más íntimo o propio de nuestra vida; y, si esa libertad fuera ilusoria, sería vana

la facultad volitiva y, de esta suerte, su ejercicio es libre de una manera mediata: en virtud de la libertad de la facultad humana de querer". Ibid., p. 400; "Libre albedrio del hombre es la capacidad que la voluntad humana tiene de autodeterminarse”. Ibid., p. 403.

32 "La no obturación conviene a la persona en virtud de aquello que le es más propio y formal, a saber, la inteligencia y la voluntad, una suerte de 'aperturas' en su ser 'físico' - por mejor decir, en su naturaleza - que le permite estar abierto a la totalidad de lo real”. J. M. Barrio, "Libertad trascendental y educación”, en: Anuario Filosófico, 1994 (27/2), p. 529.

33 EL., p. 50. Asimismo en el artículo "Cinco lecciones sobre la libertad" afirma que "en el pensar conceptual está ya el núcleo de la libertad”. CLL., p. 60.

34 Cfr. EL., p. 179. 
también la pretensión de asumir nuestro ser como capaz de decidir sobre sí mismo, aunque en principio se encontrase abierto a toda la realidad ${ }^{35}$.

Esta libertad (libre albedrío) radica en 'la determinación concreta de los medios' y, más que en ella, en que el hombre se 'autodetermina' al producir medios. Para este pensador, el 'determinar' los medios y el 'determinarse' a sí mismo denota libertad de albedrío. En esta publicación vincula el 'libre albedrío' a la voluntad, tesis que secunda en otras obras ${ }^{36}$. En otros escritos este filósofo español habla de 'autorrealización' mediante la libertad, entendiéndola en el sentido de que el hombre llegue a ser el que $\mathrm{es}^{37}$, lo cual es coherente con su visión del hombre, pues si considera que éste es una 'sustancia fija' en la que sólo cambian los accidentes, el fin de éstos será ajustarse a la sustancia. Por lo demás, en esta misma obra añade que 'el libre albedrío hace posible la libertad moral'. De ésta última afirma que, a distinción de la 'libertad fundamental' y del 'libre albedrío', que el autor admite como naturales, ésta es adquirida: 'se consigue de un modo irreductiblemente individua $^{\beta 8}$ ', en el sentido de que 'se la da el hombre a mismo'. Esta libertad perfecciona la capacidad de elegir en el sentido de que puede usar correctamente de ella, uso que se llama 'virtud moral' y radica asimismo en la voluntad (no en el intelecto).

En Economía y libertad Millán-Puelles enseña que

35 Ibid., p. 148.

36 Cfr. FF., p. 375; LF., p. 403.

37 Cfr. CLL., p. 63 a.

38 Cfr. EL., p. 237. 
'somos libres', o sea, no estamos hechos del todo; pero 'somos', o sea, tampoco lo tenemos todo por hacer. Para que nuestro libre hacernos sea realmente una tarea efectiva es menester que ya seamos de algún modo unos seres reales, algo en lo que ya existe un cierto haber natural: una naturaleza y, por lo tanto, unas inclinaciones naturales ${ }^{39}$,

lo cual indica que hace girar el peso de la libertad sobre el 'hacerse', el 'obrar' humano (accidente), no sobre el plano constitutivo del 'ser' (sustancia). En suma, entiende que el 'libre albedrío' es constitucional, mientras que la 'libertad moral' es adquirida. Como se ve, el autor secunda también aquí el modelo sustancia-accidentes en antropología, según el cual admite que es en la sustancia humana en la que "se da la libertad, aunque ella misma no es pura libertad cuando no es a la vez un puro ser. No está en este caso el hombre; de manera que en él no sólo hay, sino que tiene que haber, algo que no consiste en libertad - por tanto, algo que es en él naturaleza-" ${ }^{40}$. Como se aprecia, en esta explicación afloran dos mentalidades: una clásica, la de considerar al hombre como sustancia y predicar la libertad como accidente de aquélla; y otra moderna, la de explicar al hombre como una naturaleza no libre a la que va unida la libertad (es decir, la contraposición - more kantiano- entre naturaleza y libertad). En definitiva, el hombre cuenta con una libertad fundamental propia de ciertos accidentes, y, llegado un momento en su vida,

39 EL., p. 305. "El hacerse que le es necesario al hombre por la razón de ser hombre es precisamente un libre hacerse, mas no tan libre que no presuponga un cierto haber natural, en el que entra por lo pronto el libre albedrío que realmente tenemos como algo que no nos damos, sino con lo cual nos encontramos". Ibid.

$40 \mathrm{Ibid}$. 
el asume 'humanamente' esa libertad con la que ya contaba, pero que no era asumida por él de una manera 'propiamente humana' ${ }^{41}$.

De modo semejante, en Sobre el hombre y la sociedad Millán-Puelles entiende la libertad como "un poder que nos hace, en cierto modo, autores de nuestro ser, aunque sobre la base de una inmutable esencia metafísica, cuya entera realidad nos viene dada" ${ }^{42}$. En esta obra el autor expone la antítesis entre 'naturaleza' y 'libertad' propia de la filosofía moderna y contemporánea; luego manifiesta que él propende a una 'síntesis' entre ambas sin excluirlas, de modo similar — declara - a la que se daba entre ellas en la 'Escuela'. Afirma que "a lo largo del cambio, esta naturaleza (la humana) sigue idéntica. Es algo fijo, como principio de comportamiento. Mas no es lo mismo ser un principio fijo de comportamiento, que ser un principio de comportamiento fijo" ${ }^{43}$, lo que equivale a decir que los cambios libres son accidentales, no sustanciales, y, en consecuencia, que tanto la libertad como las potencias que son su condición de posibilidad — la inteligencia y la voluntad- son accidentes de la sustancia hombre ${ }^{44}$.

Por su parte, en su artículo "El sentido trascendente de la existencia y la educación" describe tres dimensiones de la libertad: la 'trascendental', la cual

41 Cfr. EL., pp. 313-314.

42 SHS., p. 20.

43 SHS., PP. 36-7.

44 Cfr. SHS., p. 48. 
objeto de nuestro espíritu, la libertad trascendental que éste posee resulta intensivamente concentrada en sus actos de concebir y amar a Dios ${ }^{45}$.

Nótese que si en obras anteriores sostenía que esta libertad es la apertura nativa de la inteligencia a toda verdad y de la voluntad a todo bien, ahora se añade que tales aperturas posibilitan asimismo nuestro acceso a $\operatorname{Dios}^{46}$. Otra libertad que aquí describe es:

la 'libertad de albedrío'... (que) nos remite también a Dios como su íntimo origen personal. Ciertamente esta libertad nos da un poder por el que somos origen de un sector de nuestras operaciones. Merced al libre albedrío, el hombre es dueño de sus propios actos ${ }^{47}$.

\section{La tercera es:}

la 'libertad moral' — como libertad no innata sino adquirida - (que) hace de Dios, el máximo bien común, el objeto al que tiende libremente la potencia humana de querer. Es la máxima altura a la que nuestra voluntad puede elevarse, y merece efectivamente el nombre de libertad, sin ninguna reserva ni limitación, por liberarnos, en nuestras actividades voli-

45 STE., p. 59.

46 Para un estudioso del pensamiento de Millán, "la apertura a una infinitud que trasciende al hombre constituye, a nuestro juicio, la característica principal de la antropología de MillánPuelles”. A. Gutiérrez Rosado, La naturaleza bumana como realidad trascendente en el pensamiento de Antonio Millán-Puelles, Tesis Doctoral, Roma, Universidad de la Santa Cruz, 2006, p. 240. Tal apertura se realiza, explica este autor, por la intencionalidad de la razón y voluntad.

47 Ibid. 
Naturaleza y Libertad. Revista de estudios interdisciplinares. Número 4, 2014. ISSN: 2254-9668

tivas, de todo cuanto aminora la amplitud del horizonte objetivo de estas mismas actividades ${ }^{48}$.

Respecto de esta tipología de las libertades humanas, otro tanto se lee en su trabajo "Amor a la libertad", donde Millán escribe que

la libertad ofrece, por una parte, una dimensión innata y, por otro lado, un aspecto 'moral' en el sentido de lo que se adquiere por medio del ejercicio del poder de elegir... A la primera de las dimensiones señaladas corresponde la 'libertad de albedrío', nuestro poder de elegir, y, a modo de condición o supuesto de ella, la llamada 'libertad trascendental', que es la irrestricta amplitud o universal apertura de nuestras dos potencias superiores, el entendimiento y la voluntad. En cambio, lo que se llama la 'libertad moral' —el señorío sobre las pasiones y la superación del egoísmo, que se conquistan con el recto uso de nuestro poder de opción - es un modo de libertad que libremente nos podemos conferir, una libertad libremente asequible ${ }^{49}$.

También en el libro La libre afirmación de nuestro ser distingue el autor gaditano los aludidos tipos de libertad:

A mi modo de ver - explica ampliamente-, son tres los significados cardinales del término 'libertad', si bien uno de ellos ha quedado favorecido por el uso más ordinario o más frecuente: el de la libertad de opción o libre albedrío. Justamente es la libertad en esta acepción privilegiada lo que de un modo más inmediato se comporta como necesaria condición de posibilidad de la conducta moralmente calificable, más no por ello carecen de

$48 \mathrm{Ibid}$. Una exposición de estas tres libertades se encuentra en: J. L. del Barco, "La condición humana. Naturaleza y libertad”, en: Razón y libertad, R. Alvira, (Coord.), Madrid, Rialp, 1990, pp. 137-154.

49 AL., pp. 33-4. 
todo interés para nuestro tema los otros dos sentidos cardinales del término en cuestión. A esos dos sentidos los designo respectivamente con las expresiones 'libertad trascendental' y 'libertad moral'... Doy el nombre de 'libertad trascendental'... a la constitutiva apertura de nuestro ser al ser en general y en cuanto ser — por tanto, a todos los seres-. Esta irrestricta amplitud del horizonte humano se debe al hecho de que nuestro logos no conoce fronteras en su objeto, antes bien, puede en principio hacer objeto suyo a cualquier cosa y a la falta de ella e incluso a la absoluta y pura nada... Con la expresión 'libertad moral' designo algo que no es condición de posibilidad de la conducta moralmente calificable, sino, a la inversa, un efecto de esta conducta cuando es moralmente buena de un modo habitual, no ocasional. A diferencia de la libertad trascendental y de la libertad de opción o libre albedrío, las cuales son enteramente innatas, la libertad moral es adquirida, es decir, llega a serlo, viene a ser conquistada, si en nuestro modo de ejercer el libre albedrío evitamos la servidumbre a los fines de índole material y sabemos sobreponernos a la estrechez mental de las apetencias egoístas. Fácilmente se advierte cómo la libertad así adquirida es la proporcionada por las virtudes morales, identificándose, por tanto, con el status virtutis, para cuya adquisición son necesarias, aunque no suficientes por sí solas, tanto la libertad trascendental como la de opción o libre albedrío ${ }^{50}$.

Millán-Puelles considera a la libertad trascendental como condición de posibilidad 'remota' de la moral, y al libre albedrío como 'próxima'. Por su parte, a éste lo considera doblemente: como condición próxima 'mediata' de moralidad, en tanto que propiedad de la voluntad; y como condición próxima 'inmediata', como propiedad de ciertos actos de la voluntad deliberada ${ }^{51}$.

En su libro El valor de la libertad continúa la misma clasificación de la libertad que en las obras precedentes, con la salvedad de que a la 'moral' añade aquí la 'política'. Entiende la 'libertad trascendental' como la apertura nativa 
de la inteligencia a la verdad y de la voluntad al bien. Por otro lado, habla de la 'libertad de albedrío', propia de las elecciones voluntarias. Por último, también de la 'libertad civil' y de la 'moral'. Son, pues, cinco las acepciones de la libertad que el autor menciona en estos primeros capítulos del libro. Las dos primeras — añade - son innatas; las dos últimas, en cambio, son adquiri$d a 5^{52}$. Considera asimismo libertad innata al libre albedrio ${ }^{53}$, es decir, a la capacidad de dirigirse al fin autodeterminándose en el actuar. Con él la voluntad domina sus actos e impera a las otras potencias. Añade que modalidades del libre albedrío son las clásicamente llamadas 'libertad de ejercicio' - querer o no querer-y de 'especificación' — querer esto o aquello-. Por su parte, considera adquiridas, en el plano natural, a la 'libertad moral' y a la 'libertad política' o civil, y en el plano sobrenatural, 'la libertad de los hijos de Dios ${ }^{54}$. Por otro lado, bajo la expresión 'libertad interior' agrupa a las libertades innatas y a la moral, y bajo el de 'libertad exterior', a la política. En cuanto a las descripciones de la libertad moral y política, agrega que:

\footnotetext{
en la libertad moral el hombre se auto-posee por adquirir el hábito de no someterse a sus pasiones y de trascender (sin excluir) su personal bien privado. $\mathrm{Y}$ en las libertades políticas la autoposesión consiste en el poder, que con ellas adquiere el ciudadano, de autodeterminarse en las respectivas materias sin ninguna amenaza de coacción legal y con el amparo de la ley frente a las coacciones ilegales ${ }^{55}$.
}

52 Cfr. VL., pp. 43 y 59-60.

53 "La libertad de albedrío, por ser un autodominio innato, tiene que ver con la dignidad innata del hombre como persona”. Ibid., p. 59.

54 Cfr. Ibid., p. 63.

55 Ibid., pp. 183-4. 
En su discurso “Las Humanidades y la Universidad” Millán indica que el libre albedrío es la "capacidad de autodeterminación"56. En esta disertación se advierte que la clave de la libertad humana la radica en la libertad de elección' supeditando la libertad fundamental al libre albedrío y éste a la libertad moral, porque la considera superior. Por último, en Léxico Filosófico leemos esta expresión: "apertura al horizonte ilimitado del ser. Y esa misma es la "libertad trascendental"'57.

3.3. Cuestiones abiertas: Respecto de la libertad innata, cabe preguntar, por un lado, ¿pueden tener libertad nativa la razón y la voluntad si en tal estado son potencias puramente 'pasivas'?; por otro lado, ¿en qué se distingue la 'libertad trascendental' de la voluntad del 'libre albedrío' de esta potencia, si a ambas libertades el autor las considera innatas?; en tercer lugar, ¿cómo puede ser el libre albedrío superior a las precedentes si se funda en ellas? Respecto de la libertad adquirida cabe cuestionar, por un lado, ¿cómo surge de la innata si ésta está en potencia? Por otro lado, ¿cómo ella misma pasa de la potencia al acto? En tercer lugar cabe cuestionar: ¿cómo pueden ser superiores las libertades adquiridas si nacen de las innatas, o sea, de dónde sacan el añadido?

56 HU., p. 20.

57 LF., p. 395. 
Naturaleza y Libertad. Revista de estudios interdisciplinares. Número 4, 2014. ISSN: 2254-9668

4. LA LIBERTAD HUMANA TIENE DOS DIMENSIONES MUTUAMENTE COMPLEMENTARIAS: LA CAPACIDAD DE INICIATIVA Y SU ORIENTACIÓN AL SERVICIO DEL INTERÉS GENERAL

4.1. Explicación: La primera de las dos dimensiones, la capacidad de iniciativa, indica, según Millán-Puelles, que el hombre es 'origen' de sus actos y esa disposición es tan importante que 'sin esa capacidad no se es persona'. En la segunda, el servicio al interés general, el autor enlaza la libertad con la responsabilidad, más aún, sostiene que la responsabilidad es un dimensión de la libertad ${ }^{58}$.

4.2. Ratificación textual: En Sobre el hombre y la sociedad el profesor Millán describe la libertad como "la capacidad de iniciativa al servicio de los intereses generales" ${ }^{59}$. Más adelante, en esta misma obra, añade: "yo entiendo que el auténtico concepto de la dignidad, y en definitiva de la libertad de la persona humana — tanto si es mujer como varón—, es el entrecruzamiento o el binomio de estas dos características: capacidad de iniciativa y servicio a los intereses generales"60, con lo se echa de ver que el autor radica la dignidad hu-

58 "Lo que llamamos responsabilidad no es cosa que se sobreañada desde fuera a nuestra libertad, sino, al contrario, algo que la afecta desde dentro, es decir, en virtud de su propia esencia y justo porque ésta no consiste en la sola capacidad de iniciativa”. US., p. 26. Cursivas en el original. Cfr. asimismo: AL., p. 36. En otro lugar escribe: "La responsabilidad es necesariamente heterónoma, en la acepción de que sólo es real ante alguien distinto de su sujeto, y la tesis contraria procede de la soberbia”. ML., p. 273; cursivas en el original.

59 SHS., pp. 183-4.

60 Ibid., p. 205. Y añade: "Sin capacidad de iniciativa no hay libertad ni hay dignidad de la persona humana; pero con una capacidad de iniciativa robinsonianamente puesta al servicio de 
mana en la libertad personal puesta al servicio del bien común. En esta misma línea, se lee más abajo que la vertiente cristiana de la virtud del desprendimiento es "la autodonación, que es la suprema forma de libertad"61.

Por su parte, en Universidad y sociedad Antonio Millán-Puelles pregunta: “¿qué es, en último término, la libertad? Y ¿cómo se la debe definir para po-

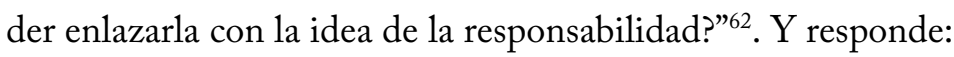

la libertad que se da en el ser humano tiene dos dimensiones mutuamente complementarias, es decir, dos aspectos, ninguno de los cuales basta por sí solo para poder definirla de una manera completa...: la capacidad de iniciativa y su orientación al servicio del interés general $^{63}$.

Por su parte, en el libro El valor de la libertad indica que la libertad moral, "el estado que consiste en la posesión de las virtudes morales" ${ }^{64}$, tiene dos facetas: el dominio de las pasiones y la elevación al bien común ${ }^{65}$. Con la libertad moral la persona humana se adapta — se 'subordina' dice el autoral bien común ${ }^{66}$. También entiende la 'libertad política' (a la que llama asi-

sí misma, es decir, con un vicioso circularismo que la hace incapaz de trascender, de salir de esa micrografía del bien particular, no hay tampoco plenitud de la dignidad de la persona humana". Ibid.

61 Ibid., p. 240.

62 US., p. 24.

63 Ibid., p. 25.

64 VL., p. 213.

65 Cfr. Ibid., p. 190.

66 Cfr. Ibid., p. 214. En consecuencia, entiende que "en tanto que aspecto o dimensión de la libertad moral, la elevación al bien común es esencialmente personal en el más estricto sentido 
mismo 'civil', 'pública', 'jurídica', 'social', 'convencional') como "un auténtico bien común, pero no el bien común único"67, que consiste en unos actos con "la doble índole de imperados, por una parte, y, por otra, de físicamente insertos en un contexto civil” ${ }^{68}$ y que dicen referencia al bien común ${ }^{69}$.

4.3. Cuestiones abiertas: A ambos aspectos de la libertad humana enunciados en esta tesis les caben sendas cuestiones: A la primera: ¿seguro que la clave de la capacidad de iniciativa radica en ser 'origen' de actos?, ¿no equivale esto a medir la libertad por lo inferior a ella, sus actos? A la segunda: ¿seguro que 'el servicio al interés general' equivale a (o agota) la 'responsabilidad', pues parece que el interés general es exclusivamente social, mientras que la libertad también se puede corresponder con el ser divino?

\section{LA LIBERTAD HUMANA RESPECTO DE SU ‘ORIGEN’ DEPENDE NECESARIAMENTE DE UN PRINCIPIO O CAUSA.}

5.1. Explicación: Para el pensador andaluz la libertad humana es originada y su origen es el ser divino. Ahora bien, entiende este origen a modo de 'causa', 'principio' o 'fundamento'.

5.2. Ratificación textual: En Fundamentos de filosofia Millán-Puelles escribe que la libertad "no implica privación de causa; antes por el contrario,

de este término, que es el correspondiente a cada una de las personas individuales (en este caso, humanas)". Ibid., pp. 222-3.

67 Ibid., p. 236.

68 Ibid., p. 237.

69 Cfr. Ibid., p. 238. 
supone una relación 'de causalidad"'70. Otras veces, en vez de 'causa', habla de 'principio"71. En su artículo "La dignidad de la persona humana" explica que Dios es el 'fundamento' y 'origen' trascendente de la libertad humana ${ }^{72}$. También en Sobre el hombre y la sociedad mantiene que Dios es origen y fundamento de la libertad ${ }^{73}$. En su trabajo "El sentido trascendente de la existencia y la educación" lo expone de este modo: el libre albedrío

\footnotetext{
nos transciende, en tanto que ninguno de nosotros es realmente su origen. Ningún hombre se da a sí mismo su libertad de albedrío, sino que se encuentra ya con ella de un modo tan natural - es decir, tan innato- como el correspondiente a otra cualquiera de sus propiedades específicas. Así, pues, nuestra libertad de albedrío es ontológicamente dependiente de la absoluta libertad de Dios, en la que estriba su más hondo origen. Esta dependencia ontológica no se opone a su ser, sino que lo hace viable cabalmente en su índole de auténtica libertad ${ }^{74}$.
}

En su libro El valor de la libertad Millán afirma, en sintonía con Kierkegaard, que el fundamento del libre albedrío humano es la omnipotencia divina $^{75}$. Y lo mismo insinúa en su Léxico Filosófico:

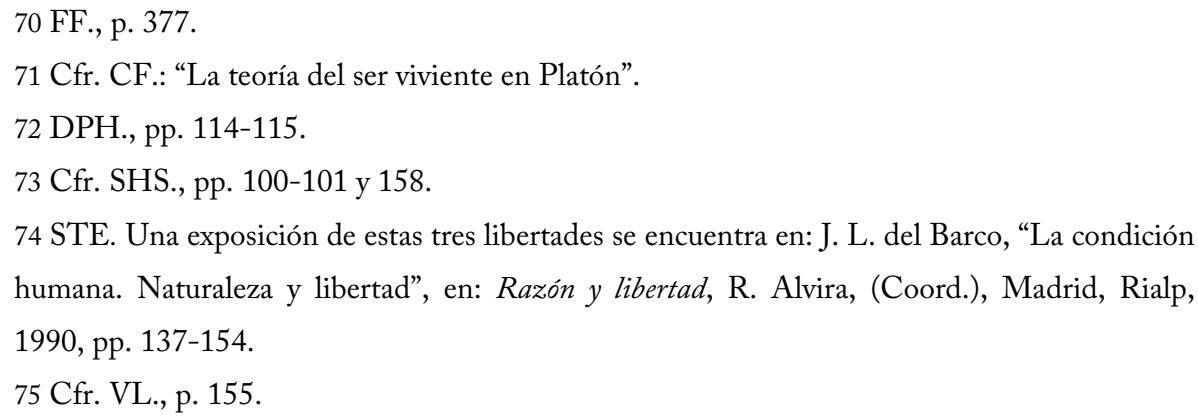


Naturaleza y Libertad. Revista de estudios interdisciplinares. Número 4, 2014. ISSN: 2254-9668

tanto el libre albedrío como la 'libertad trascendental' de la razón, que lo hace posible, son libertades que no nos podemos dar, sino que nos son dadas. Nos encontramos con ellas sin haberlas buscado ni elegido. Son, por tanto, tan naturales en el hombre como es natural en los animales infrahumanos el carecer de ellas ${ }^{76}$.

5.3. Cuestiones abiertas: A esta tesis se puede preguntar lo que sigue: ¿cómo puede ser libre la libertad si depende necesariamente de un principio, de una causa, de un fundamento, pues lo principiado, el efecto, lo fundado, depende inexorablemente del principio, de la causa, del fundamento?

\section{LA LIBERTAD HUMANA RESPECTO DE SU ‘OBJETO’, ES 'LIBERTAD DE INDIFERENCIA'}

6.1. Explicación: La expresión 'libertad de indiferencia' parece explicar que la libertad es autónoma, o sea, sin vinculación constitutiva a ninguna realidad objetiva, pues si estuviese vinculada a alguna, no podría ser indiferente respecto de ella. Antonio Millán-Puelles advierte que esta concepción se opone a la tomista 'voluntas ut natura', porque ésta se describe necesariamente por orden a un bien, el fin último. Por tanto, el filósofo de Alcalá de los Gazules se inclina por vincularla a la 'voluntas ut ratio', es decir, con la voluntad electiva que sigue a la deliberación racional ${ }^{77}$.

6.2. Ratificación textual: En una de las primeras obras de Millán se lee que la libertad "deriva de algo que no se encuentra unívocamente determinado a

76 LF., p. 395.

77 Cfr. OEH., p. 179. 
él (al hombre), sino que goza de una interior indiferencia activa para haberlo cumplido u omitido"78. En Economía y libertad añade que "el quehacer en que estriba (la economía) no se vincula necesariamente a unos determinados bienes materiales. Por ello mismo $-\mathrm{O}$ sea, por hallarse exenta de esta vinculación - tiene una evidente libertad, en el sentido de no estar sujeta a ninguna especie de estos bienes" ${ }^{\prime 9}$, lo cual denota que este pensador vincula la libertad a la panorámica de bienes con que al agente económico se puede encontrar y nota que no está determinado por ninguno de ellos.

En La libre afirmación de nuestro ser Millán-Puelles escribe:

la doble posibilidad de que, en el uso de su libertad de opción, el hombre actúe en consonancia con su propio ser específico o, por el contrario, en oposición a él, abre el camino para una interpretación del obrar éticamente recto como la forma práctica de asumir libremente nuestra propia naturaleza ${ }^{80}$.

Es patente que la libertad a la que el autor se refiere es el libre albedrio ${ }^{81}$; también que esta libertad se encuentra abierta a contrarios, lo cual él entiende en otras obras como 'libertad de indiferencia'. De acuerdo con este

78 OEH., p. 179. Cfr. asimismo FF., pp. 375, 378.

79 EL., p. 135.

80 LAS., p. 13.

81 "La libertad —en el presente contexto se ha de sobreentender que se trata, concretamente, de la libertad del albedrío- no es algo que el propio yo humano adquiera, dándoselo a sí mismo libremente, sino algo que el hombre tiene de una manera innata, i.e., por naturaleza: formando parte de lo que en él está ya hecho antes de que él mismo actúe libremente... la libertad que hay en el hombre es algo intrínsecamente fundado en la específica naturaleza de éste". Ibid., p. 35. 
modelo explicativo, Millán admite que la libertad es una capacidad nativa en el ser específico del hombre, pero que puede ser ejercida bien o mal por el yo -consciente y libre-, y que la rectitud o vileza dependen de que tal ejercicio libre - que ya no es libertad 'natural' sino 'moral'-, se conforme o no a la naturaleza humana: "la libre volición indispensable para afirmar en la praxis nuestro ser tiene su término explícito — vale decir, inmediato y directoen lo que hacemos cuando nuestra conducta es conforme a nuestra naturaleza"82. La misma tesis sostiene en su obra Ética y realismo: "Yo entiendo escribe- que el comportamiento éticamente recto es una libre afirmación de nuestro ser, no teórica, sino práctica" ${ }^{33}$.

6.3. Cuestiones abiertas: Como se ha indicado, el autor atribuye la 'libertad de indiferencia' a la voluntas ut ratio en una de sus obras. En otras reitera que ser libre es realizar acciones conformes al ser del hombre. Una pregunta que aquí se abre es: ¿es seguro que la voluntad racional es indiferente respecto de todos los objetos a los que está abierta?, pues si tal libertad es indiferente respecto de todo objeto, ¿no equivale esto a sostener que se la considera más valiosa a ella que a cualquier otra realidad y, por tanto, que está justificado que esté desvinculada de ella?

82 Ibid., p. 28.

83 ER., p. 14. “Tenemos una naturaleza —añade Millán-Puelles-, y en el uso de nuestra libertad podemos actuar en conformidad o en disconformidad con ella”. Ibid., pp. 15-6. 
Naturaleza y Libertad. Revista de estudios interdisciplinares. Número 4, 2014. ISSN: 2254-9668

7. LA LIBERTAD HUMANA DERIVA DE LA NECESIDAD Y SE SUBORDINA A ELLA

7.1. Explicación: Por una parte, de acuerdo con el modelo sustancia-accidentes que Antonio Millán-Puelles usa para describir al hombre, hay que decir que lo que puede cambiar son los accidentes, no la sustancia. Por tanto, si la libertad es del plano de los accidentes, se tiene que supeditar a la necesidad de la sustancia. Por otra parte, si su origen es el ser divino y éste es el ser necesario, la libertad humana tiene un 'origen' necesario. Por lo demás, si tanto las libertades innatas como las adquiridas están abiertas a Dios, y éste es el ser necesario, la libertad tiene un 'fin' necesario.

7.2. Base textual: Desde el inicio de su trayectoria filosófica el pensador andaluz escribió que "la libertad exige, pues, una fundamental necesidad... Soy libre, en suma, porque poseo un ser determinado" ${ }^{84}$. En obras siguientes sigue vinculando la libertad a la necesidad" ${ }^{85}$ También en el artículo "En torno a la idea del "yo"' el papel de la libertad no es sino aceptar moralmente la necesidad. De aquí surge la que el autor llama 'ética de la libre aceptación de nuestro ser' necesario. En Sobre el hombre y la sociedad mantiene asimismo que de lo necesario, la naturaleza humana, surge lo libre ${ }^{86}$.

84 ILJ., p. 65.

$85 \mathrm{La}$ persona es "un ser que por tener, no sólo instintos, sino también entendimiento y libertad, es capaz de sentir necesidades morales, tanto con relación a su cuerpo como con respecto a su espíritu, y que, por ello, tiene también derecho a satisfacer esta doble clase de necesidad”. PHJS., p. 14.

86 Cfr. SHS., p. 50. 
7.3. Cuestiones abiertas: Como esta tesis implica admitir que la necesidad es superior a la libertad, cabe cuestionar lo que sigue: ¿jeguro que esta jerarquía es real? ¿No será más bien la 'necesidad' una noción modal que se opone a otra noción lógica, la 'posibilidad', mientras que la libertad es una noción que designa a una realidad?

\section{LA LIBERTAD HUMANA ES LIMITADA}

8.1. Explicación: Antonio Millán-Puelles acepta que la naturaleza o sustancia humana es finita, y como mantiene que la libertad es un accidente propio de tal naturaleza o sustancia humana, en consecuencia, no puede sino afirmar que la libertad humana es finita, pues de lo contrario, el accidente sería superior a la sustancia y heterogéneo respecto de ella.

8.2. Base textual: En Persona humana y justicia social el pensador español defiende la limitación de la libertad ${ }^{87}$. En cambio, en La estructura de la subjetividad sostiene la libertad es el remedio a la constitutiva finitud humana ${ }^{88}$, lo cual parece no armonizar con la precedente tesis acerca de que la libertad sea limitada, tesis que, por lo demás, también mantiene en esta obra. En su artículo "La formación de la persona" el pensador andaluz escribe:

dada la limitación del ser humano, nada en éste es absoluto o infinito. Nuestro libre albedrío es una libertad relativa, limitada, condicionada. Pero una libertad relativa, limitada,

87 Cfr. PHJS., p. 13.

88 Cfr. ES., p. 234. 
condicionada no deja de ser una libertad, de la misma manera que el entendimiento finito que los hombres tenemos no deja de ser un verdadero entendimiento ${ }^{89}$.

En La estructura de la subjetividad admite asimismo que, en cuanto sustancia, la subjetividad es limitada; y en cuanto fáctica, su libertad también lo $\mathrm{es}^{90}$. En Sobre el hombre y la sociedad, al concebir a la libertad como predicamental y verla basada en una naturaleza dada y restringida, necesariamente la comprende como limitada por ese 'sustrato" ${ }^{\text {'. }}$

En su libro El valor de la libertad afirma que las dos libertades fundamentales, las nativas de la inteligencia y de la voluntad, son 'finitas' porque dependen de un ser finito, el hombre, y que sólo cabe llamarlas infinitas relativamente, a saber, por sus objetos (la verdad y el bien), es decir, en cuanto a su respectiva capacidad de conocer y de querer toda realidad ${ }^{92}$. Millán considera asimismo 'limitadas' tanto la libertad política como la moral $-\mathrm{y}$ también las tres que llama innatas-, pero de la política dice, además, que 'impone límites" ${ }^{93}$, pues "esencialmente está orientada a evitar las intromisiones que cualquier ciudadano puede sufrir por el abusivo ejercicio del libre

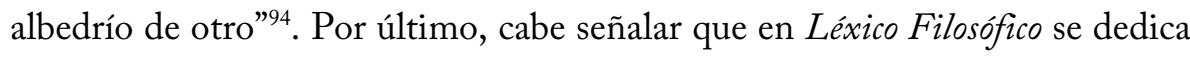
una sección al libre albedrío, y de este se declara que "la libertad posible en

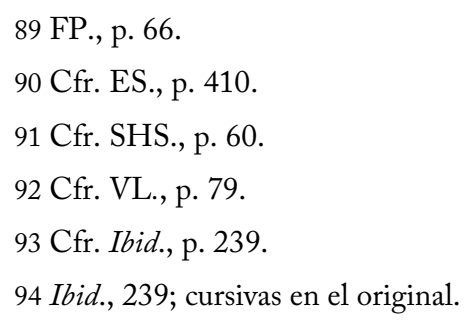


un ser limitado o relativo es, necesariamente, una libertad limitada o relativa"95.

8.3. Cuestiones abiertas: De ser limitada la libertad humana, cabe preguntar varias cosas: ¿Por qué se dice que la libertad trascendental nativa está abierta a todo?, ¿la libertad adquirida puede crecer progresivamente?, ¿'en virtud de qué?, Y si crece 'progresivamente', ¿dónde radica su límite? Además, de la libertad adquirida se dice que puede elegir a Dios. Ahora bien, ¿cómo una libertad limitada puede corresponderse con una realidad ilimitada?

\section{LA FORMA MÁXIMA DE LIBERTAD ES LA ‘ELECCIÓN’ DE DIOS, PROPIA DEL LIBRE ALBEDRÍO}

9.1. Explicación: El objetivo que parece albergar Antonio Millán-Puelles en esta tesis es el de poner en correlación la libertad humana con el ser divino como su 'objeto' principal. Ahora bien, es claro que esa correlación la establece en términos de 'elección' o 'decisión', acto propio de la voluntad. Y como tanto esta facultad como sus actos son considerados por él como accidentes, tal vez esto fuerce a admitir que la vinculación del ser humano al divino sea accidental. Veamos.

9.2. Base textual: La 'elección' o ‘decisión' es, para el profesor Millán -y desde el comienzo de su obra-, el acto fundamental de la libertad mediante 
el cual nos determinamos a nosotros mismos ${ }^{96}$. En su artículo "Cinco lecciones sobre la libertad" sostiene que la libertad religiosa es "la forma máxima de libertad', e indica que "el que, en uso de su libertad, no ha elegido todavía a Dios no ha trascendido ciertos límites de la libertad, es decir, no ha saturado todas las posibilidades de la libertad"97, expresión que recuerda a las de Kierkegaard. En "Amor a la libertad" también vincula el libre albedrío a Dios en estos términos: "la libertad enteramente indispensable para que el hombre ame a Dios es la innata o congénita y, formalmente, la propia del albedrío" 98 .

Por su parte, en su libro El valor de la libertad el pensador andaluz mantiene que la 'libertad de arbitrio' es la libertad de elección ${ }^{99}$, que no versa sólo sobre los bienes externos (libertad de especificación), sino también sobre los propios actos (libertad de ejercicio), pues no sólo se puede querer esto o lo otro, sino también querer o no querer. La describe conforme al modelo clásico de 'dominio sobre nuestros actos'. Esto parece incluir implícitamente un equívoco, pues antes hemos visto que, para él, el libre albedrío es innato, mientras que ahora nos dice que su acto fundamental es la elección, siendo claro que este acto es adquirido. A esto añade, de modo afín a Cornelio Fabro, que la suprema concentración de la libertad de elección estriba en la

96 Cfr. "Al decidirme, yo me hago a mí mismo, promoviendo mi ser, esto es, determinándome a mí mismo a ser". ILJ, p. 62; "la libertad es la propiedad por la que un ser se determina a sí mismo desde el fondo de su propia intimidad”. Ibid., p. 64. Cfr. también EIJ, p. 190; SHS., p. 52. Escuetamente lo describe en otro lugar "en todo elegir me elijo". VL.. p. 198 97 CLL., p. 62 b.

98 AL., p. 34.

99 Cfr. VL., p. 106. 
elección del Absoluto, lo cual equivale al paso del libre albedrío, que considera innato, a la libertad moral, que es adquirida.

9.3. Cuestiones abiertas: A esta sentencia cabe preguntar dos series de cuestiones: Por una parte, si se admite que 'elegir' a Dios es propio del libre albedrío y que tal 'elección' es 'la forma máxima de libertad', ¿por qué se dice que la libertad moral es superior al libre albedrío?, ¿acaso el elegir a Dios del libre albedrío se identifica con un acto de la libertad moral? Pero si el autor ha distinguido previamente el libre albedrío y la libertad moral, ¿cómo hacerlos ahora equivalentes? Por otra parte, si según el planteamiento tomista, tanto el libre albedrío como su acto de elegir son propios de la voluntad y versan exclusivamente sobre medios, no sobre el fin último, ¿̇se puede, en rigor, 'elegir' a Dios? ¿No será que la correspondencia de la libertad personal humana con Dios no es la de elegirle, sino otra diversa? Y si lo es, ¿¿cuál?

\section{BIBLIOGRAFÍA EMPLEADA}

Arana, J., "Necesidad, libertad, Azar", Realidad e irrealidad. Estudios en homenaje al Profesor Millán-Puelles, Madrid, Rialp, 2001, pp. 17-32.

Barrio, J. M., "Libertad trascendental y educación”, Anuario Filosófico, (27/2) 1994, pp. $527-540$.

- "Dignidad y trascendencia de la persona. Una panorámica de la antropología de Antonio Millán-Puelles”, en Propuestas antropológicas del s. XX (I), J. F Sellés (ed.), Pamplona, Eunsa, 2a ed., 2006.

Bicocca, M., La persona humana y su formación en Antonio Millán-Puelles, Pamplona, Eunsa, 2011.

Del Barco, J. L., "La condición humana. Naturaleza y libertad", Razón y libertad, R. Alvira, (Coord.), Madrid, Rialp, 1990, pp. 137-154. 
Naturaleza y Libertad. Revista de estudios interdisciplinares. Número 4, 2014. ISSN: 2254-9668

Eres Brun, J. J., La libre realización del hombre según Antonio Millán-Puelles (Fundamentos para una antropologia), Tesis Doctoral, Roma, Universidad de la Santa Cruz, 2005.

Gutiérrez Rosado, A., La naturaleza bumana como realidad trascendente en el pensamiento de Antonio Millán-Puelles, Tesis Doctoral, Roma, Universidad de la Santa Cruz, 2006.

Martínez López, F. J., La fundamentación de la ética realista. Valoración de la propuesta de $A$. Millán-Puelles, Tesis Doctoral, Roma, Universidad de la Santa Cruz, 1999.

Melendo, T., "Las dimensiones de la libertad", Anuario Filosófico, (27/2) 1994, pp. 583602.

Millán-Puelles, A., “La idea de la libertad en Jaspers", Arbor, (65) 1951, pp. 61-65.

—-, Ontología de la existencia histórica, Madrid, ed. J. Pueyo, 1951.

—, Fundamentos de filosofia , Madrid, Rialp, 2 ed., 1958.

—_, "Maeztu y la defensa del espíritu", Madrid, Amigos de Maeztu, 1957.

—, La claridad en filosofia y otros estudios, Madrid, Rialp, 1958.

—, Persona humana y justicia social, Madrid, Rialp, 5ª ed. 1982.

—- La formación de la personalidad humana, Madrid, Rialp, 1963.

__, "La dignidad de la persona humana", Atlántida (IV/14) 1966, pp. 573-577.

—_, La estructura de la subjetividad, Madrid, Rialp, 1967.

—, "En torno a la idea del 'yo", Estudios de Metafísica, 1971, pp. 9-13.

—_, Economía y libertad, Madrid, Confederación Española de Cajas de Ahorro, 1974.

—, Universidad y sociedad, Madrid, Rialp, 1976.

—-, "Cinco lecciones sobre la libertad", Revista de Medicina de la Universidad de Navarra (XXV/1) 1981, pp. 59-63.

—_, "E1 sentido trascendente de la existencia y la educación", Revista Española de Pedagogia (XL/158) 1982, pp. 57-60.

—, "Amor a la libertad", AA.VV., Homenaje a Monseñor Josemaria Escrivá de Balaguer, Pamplona, Eunsa, 1986, pp. 25-49.

—, "Maeztu y la libertad", Razón Española (IV/29) 1986, pp. 261-276.

—, "La formación de la persona", AAVV., El pensamiento filosófico-pedagógico de Jacques Maritain, Madrid, San Pablo CEU, 1988, Colección Anales, nº, 3, pp. 65-66.

—_ La libre afirmación de nuestro ser, Madrid, Rialp, 1994.

—- El valor de la libertad, Madrid, Rialp, 1995.

__, Ética y realismo, Madrid, Rialp, 1996. 
Naturaleza y Libertad. Revista de estudios interdisciplinares. Número 4, 2014. ISSN: 2254-9668

—_, "Las Humanidades y la Universidad”, Intus-Legere (1) 1998, pp. 16-28.

—, Léxico filosófico, Madrid, Rialp, 2a ed. 2002.

Juan Fernando Sellés

jfselles@unav.es 